\title{
Finite element analysis of double layer metal bellows flexible hose for chemical pipeline

\author{
Weijie Du ${ }^{1, a)}$, He-hui Wang ${ }^{1, b)}$, Shidong Wen ${ }^{1, c)}$ \\ ${ }^{1}$ School of Mechanical Power Engineering, East China University Of Science And Technology, \\ Shanghai 200237, China \\ a)duweijieecust@163.com, b) hhwang@ecust.ecu.cn
}

Key Words: metal bellows flexible hose; wire braid; finite element method; ANSYS

\begin{abstract}
Multi-layer metal bellows flexible hose is a widely used compensating element in the chemical piping system, playing a role in displacement compensation, vibration isolation and noise reduction. The three-dimensional finite element model of double layer metal bellows flexible hose with wire braid was established in ANSYS, strength and stiffness analysis is conducted, and the stress and strain distribution of double layer bellows are obtained. It was proved that the wire braid can strengthen the metal hose by comparing the performance of bellows with or without wire braid. It was found through this analysis that the structural parameters of the metal hose designed by traditional methods are too conservative. The results provide a reference for the design and application of multi-layer metal bellows flexible hose.
\end{abstract}

\section{Introduction}

The metal bellows flexible hose is the connected and compensation device of the chemical pipeline, possessing excellent performance of sealing, compressive, temperature resistance, corrosion resistance, flexibility and fatigue resistance, absorption of vibration and noise etc. Metal hose is becoming increasingly indispensable to the modern engineering[1].

The traditional study on metal hose often use theoretical research, with the development of the finite element technology, study on metal hose using the finite element method is increasingly common. In this paper, a chemical company with multilayer metal hose was taken for example, finite element model was created to analyze the strength and stiffness of the metal hose. The distribution of stress and strain of bellows is obtained, and the effect of wire braid on metal hose is analyzed, which all provide a reference for understanding and application of the metal hose.

\section{Brief introduction of metal hose model}

\subsection{The structure of metal hose}

According to the definition in the national standard 14525-2010 GB/T "General specification for corrugated metallic hose assemblies"[2], metal hose is a combination of bellows, wire braid and joint. The structure[1] of metal hose is shown in Figure 1.

Braids and metal hose have the same material 0Cr18Ni9(SUS304), elastic modulusE $=1.96 \times$ $10^{5} \mathrm{MPa}$, Poisson's ratio $v=0.3$, yield limit $\sigma_{0.2}=206 \mathrm{MPa}$, tensile limit $\sigma_{\mathrm{b}}=520 \mathrm{MPa}$, the yield limit of the molding material is calculated by using table lookups[6], $\sigma_{0.2}=328 \mathrm{MPa}$. 


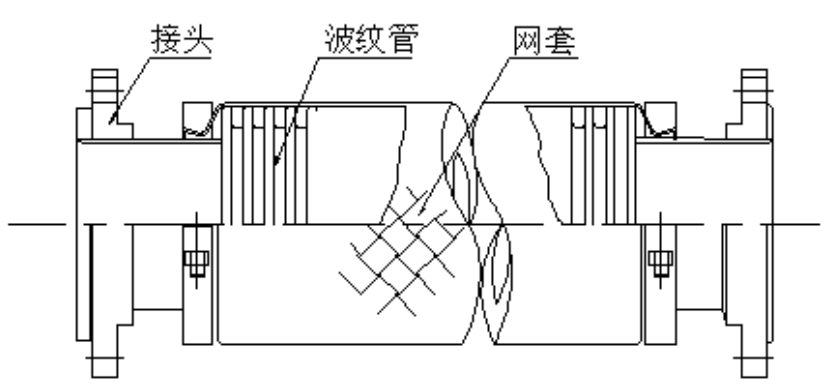

Fig.1 Metal hose structure diagram

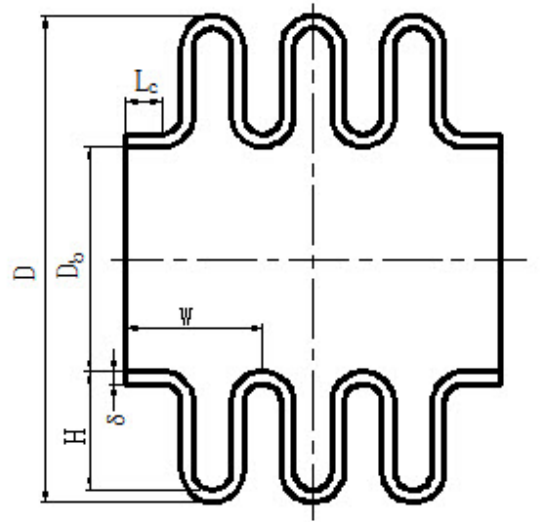

Fig. 2 Structural of U-shaped bellows

\subsection{Finite element model of metal hose}

The structure of the U-shaped bellows[3] is shown in Figure 2. The structure parameters of bellows were shown in Table 1.

Table 1 The structure parameters of bellows

\begin{tabular}{|c|c|c|c|c|c|c|c|}
\hline Nominal & Wave Root & Wave & Wave & Layer & Layer & Wave & Length \\
Diameter & Diameter & Height & Length & Thickness & Number \\
$D_{(\mathrm{mm})}$ & $D_{b}$ & $h$ & $q$ & $\delta$ & $n$ & $N$ & $\begin{array}{c}\text { Number } \\
N\end{array}$ \\
\hline 450 & 480 & 44 & 55 & 1.7 & 2 & 5 & 20 \\
\hline
\end{tabular}

Three-dimensional model of the double layer bellows was created by solid185, and meshed based on mapping method to ensure that element has a better shape, contact pairs[4] were established between layers. Wire braids parameters were shown in Table 2, which can be got by empirical formulas[6] and GB/T 14525-2010 "General specification for corrugated metallic hose assemblies"[2].

Table 2 Wire braids parameters

\begin{tabular}{|c|c|c|c|c|c|}
\hline Braid angle & Total carriers & Wires per carrier & Wire diameter & Layer number & Weaving density \\
\hline$\alpha$ & $\mathrm{m}$ & $\mathrm{n}$ & $\mathrm{d}(\mathrm{mm})$ & $\mathrm{c}$ & $\lambda$ \\
\hline $30^{\circ}$ & 96 & 33 & 0.6 & 2 & $95 \%$ \\
\hline
\end{tabular}

Wire braids can be regarded as tracks that a point in the outer surface of the bellows rotate around the central axis of the bellows and move along the busbar of the bellows uniformly at the same time. The parameter equation is in the literature[5]

Three node space beam element Beam189 was selected according to the structural characteristic of the braid[6]. The section of the beam is defined as circle section. Section area is equal to that of braid per share. so the section area should be double expanded, which is to say that the section diameter is $4.87 \mathrm{~mm}$.

\subsection{Apply loads and constraints}

The bellows crest keep in contact with the braids when the metal hose deforms, the friction force between them can be ignored. Relative slip along the circumference and the axial direction is allowed between bellows crest and braids, while they have the same displacement in the radial direction[6]. Coupling manner is selected to indicate the nodal displacement relationship between braids and bellows after deformation. The axial degree of freedom UZ at the end of the bellows and braids was coupled. The result after coupling is shown in Figure 3. 

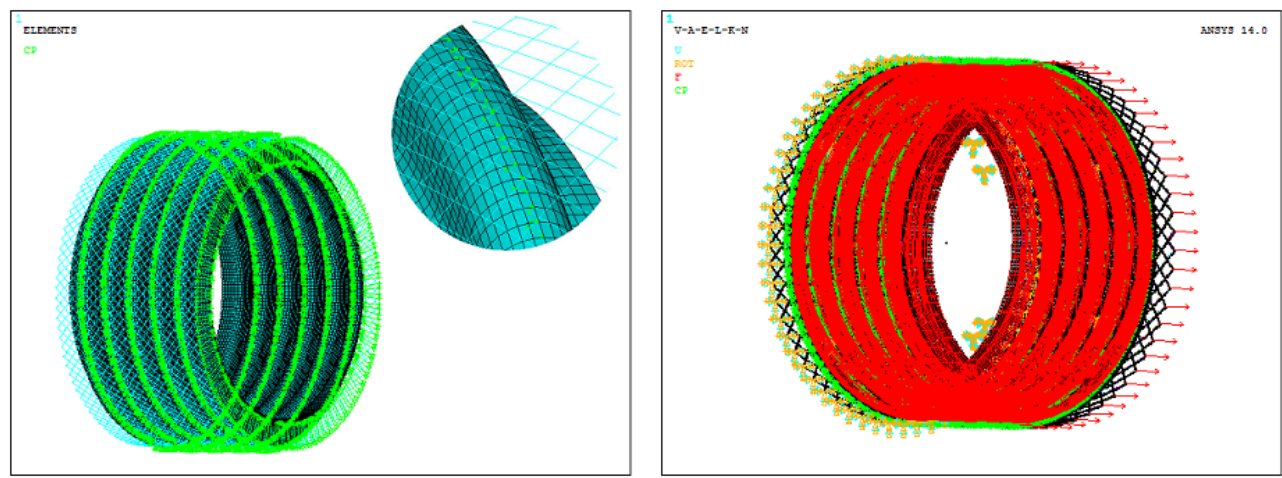

Fig. 3 Bellows and braids node-coupling diagram Fig.4 Metal hose loads and constraints diagram

Pressure load $\mathrm{P}=3.0 \mathrm{MPa}$ in the inner surface of the bellows and the axial tension $\mathrm{F}$ at the end of the bellows were applied. The modal after applying loads and constraints is shown in Figure 4 .

\section{Result analysis}

\subsection{Axial stiffness analysis}

Axial displacement of the metal hose is shown in Figure 5, it can be seen that the maximum value of the axial displacement is $1.43 \mathrm{~mm}$ in the free end of the metal hose. The axial stiffness is calculated from Equation as follows:

$$
K=\frac{F}{S}
$$

$\mathrm{F}$ is axial force which is the product of inner pressure and the section area of the bellows $F=477 K N$, $\mathrm{S}$ is axial displacement $S=1.43 \mathrm{~mm}$, the axial stiffness $K=333.6 \mathrm{KN} / \mathrm{mm}$.According to the equation in the standard[7],the axial stiffness of double layer bellows is calculated $18.3 \mathrm{KN} / \mathrm{mm}$ after conducting similar calculations. So the axial stiffness of bellows with net is 18 times of that of the bellow without braids. It is reasonable to ignore the axial stiffness of the bellows when research on metal hose.

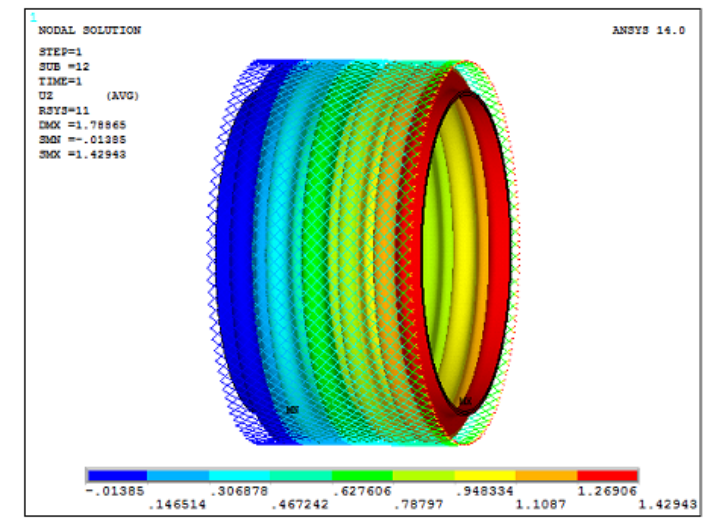

Fig.5 Axial displacement of metallic hose

\subsection{Strength analysis}

In order to analyze the influence of braids on the strength of bellows, the stress distribution of the bellows with braids is compared to that without braids. Figure 6 and Figure 7 show the equivalent Mises stress of the bellows with and without braids respectively. It can be seen that the largest equivalent Mises stress of the bellows with braids is $194.4 \mathrm{MPa}$, while that of the bellows without braids is $335.3 \mathrm{MPa}$. The stress of the bellows crests and troughs without braids is all largest, while the stress of the bellows crests is also largest but that of the bellows troughs is lowered obviously after added braids, even close to the minimum value. 

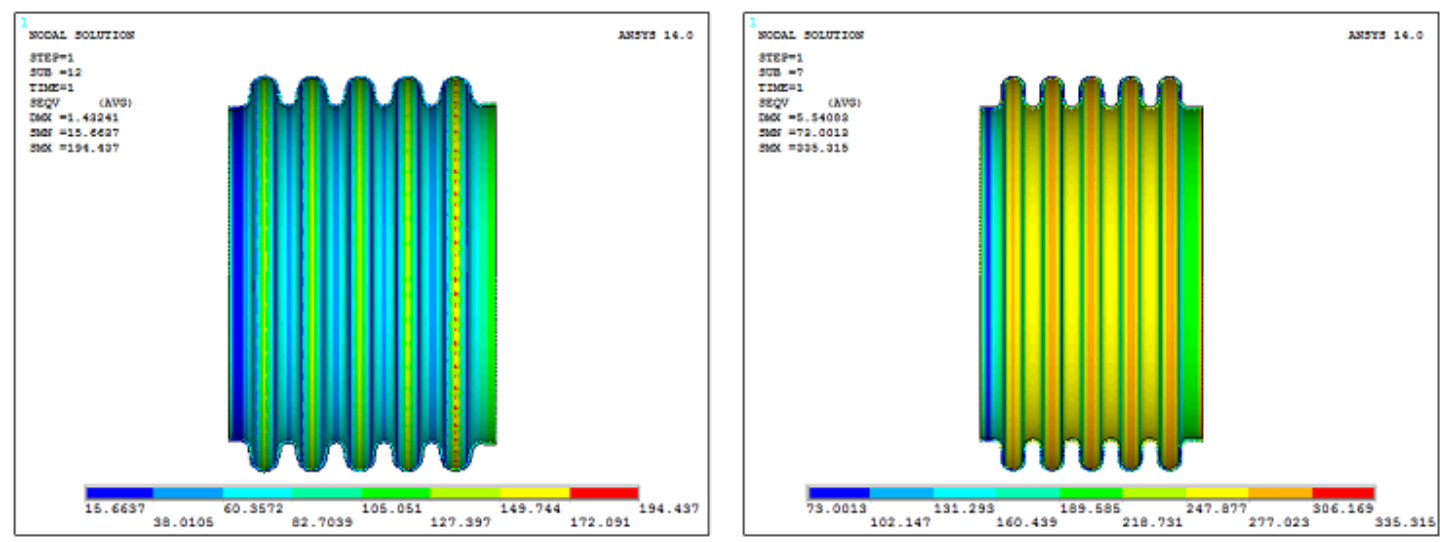

Fig.6 Mises stress of outer layer(with braids) Fig.7 Mises stress of outer layer(without braids)

\subsection{Strength check}

The strength of the bellows and the braids all should be checked. It can be seen from Figure8 that the maximum stress of the bellows is $217.9 \mathrm{MPa}$, which is smaller than the yield strength 328MPa, so the strength of the bellows can meet the requirement. The wire braids mainly bear tension, so we should check the tensile strength of the braids. The axial stress distribution of the beam was shown in Figure9.

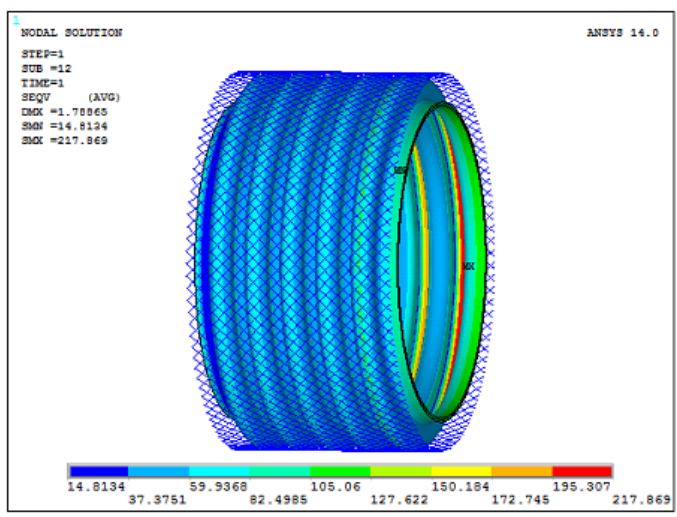

Fig.8 Mises stress of metallic hose

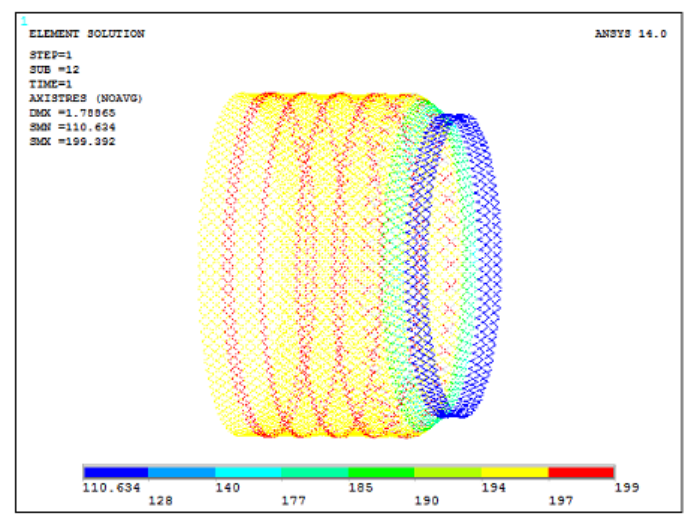

Fig.9 Axial stress of braids

It can be seen that the largest axial stress of braids locating in the position which contact with bellows crests is $199 \mathrm{MPa}$ much smaller than tensile strength 520MPa, so the design of net is save. Double layer braids are chose in this design which has 33 steel wires per share, equal to 66 steel wires in single layer. This design has met the requirement, and the theoretical method of single layer requires 96 wires is too conservative[3].

\section{Conclusion}

(1) Based on ANSYS software, the carrying capacity of corrugated metal hose under the internal pressure and axial force is analyzed and the strengthening of the net on the metal hose is analyzed, which all provide a reference for design and application the metal hose.

(2) The axial stiffness of bellows with net is 18 times of that of the bellow without net, so the axial stiffness of the bellows can be ignored and decided by net, The stress of the bellows is lowered obviously after adding net, which shows that the net has a strengthening effect on the bellows; the net designed according to the theoretical method is too conservative.

\section{Reference}

[1]. Z.Y. Ge, Metal Hose, Yuhang-Publishing Inc., Beijing, (1985) (In Chinese)

[2]. GB/T 14525-2010 General specification of metal bellows flexible hose, S, 2011(In Chinese)

[3]. GB/T 12777-2008 General specification of metallic bellows expansion joints, S, 2008 
[4]. Y.J. Yang, X.F. Wang, Nonlinear finite element analysis of multi-layer bellows, J, Pressure Vessel, 2003, 20(9) (In Chinese)

[5]. Q.X. Liu, Determination of the parameters of metal hose wire braids, J, Pipeline technology and equipment, 1997, (In Chinese)

[6]. S.J. Han, The finite element parametric modeling method of the metal hose based on ANSYS, J, Manufacturing Automation, 2011, 33(10):125-127(In Chinese)

[7]. GB/T 12522-2009 Stainless steel bellows expansion joint, S, 2009(In Chinese) 